\title{
Effect of lanthanum chloride on tumor growth and apoptosis in human ovarian cancer cells and xenograft animal models
}

\author{
FEN WANG ${ }^{*}$, YUANFANG ZHU*, SHANYU FANG, SHUYA LI and SISUN LIU \\ Department of Obstetrics and Gynecology, The First Affiliated Hospital of Nanchang University, \\ Nanchang, Jiangxi 330006, P.R. China
}

Received August 18, 2016; Accepted May 15, 2017

DOI: $10.3892 /$ etm.2018.6299

\begin{abstract}
Ovarian cancer is the leading cause of mortality resulting from gynecologic cancer. A common anti-ovarian tumor drug is cisplatin; however, repeated use of cisplatin causes severe resistance and leads to poor long-term survival rate in ovarian cancer patients. Recently, it was reported that lanthanum chloride $\left(\mathrm{LaCl}_{3}\right)$ may inhibit tumor growth and induce apoptosis in certain cancer cells. In the present study, the effect of $\mathrm{LaCl}_{3}$ on ovarian cancer was determined in vivo and in vitro. A cisplatin-sensitive human ovarian cancer cell line, COC1, was used in the current study. A xenograft animal model of ovarian cancer was established injecting $\mathrm{COC} 1$ or cisplatin-resistant $\mathrm{COC} 1$ cells (COC1/DDP) cells into mice. A TUNEL assay was used to determine the apoptosis of the $\mathrm{COC} 1$ or $\mathrm{COC} 1 / \mathrm{DDP}$ cells and a immunohistochemical assay was conducted to measure the expression of B-cell lymphoma-2, Ki67, breast cancer 1 (BRCA)1, BRCA2 and excision repair cross-complementation group 1 in $\mathrm{COC} 1$ or COC1/DDP cells. It was observed that $\mathrm{LaCl}_{3}$ promoted apoptosis in COC1 and COC1/DDP cells. In addition, $\mathrm{LaCl}_{3}$ plus cisplatin led to further increase in the expression levels of tumor suppressor genes and decrease in the expression of oncogenes. Furthermore, application of $\mathrm{LaCl}_{3}$ and cisplatin inhibited tumor growth in vivo in a xenograft animal model. These results indicated the synergistic role of $\mathrm{LaCl}_{3}$ on cisplatin-induced inhibition of cancer cell proliferation and tumor growth, providing a potential and effective candidate for the treatment of ovarian tumors.
\end{abstract}

Correspondence to: Dr Sisun Liu, Department of Obstetrics and Gynecology, The First Affiliated Hospital of Nanchang University, 17 Yongwaizheng Street, Nanchang, Jiangxi 330006, P.R. China

E-mail: sisunliu122@sina.com

*Contributed equally

Key words: lanthanum chloride, cisplatin, $\mathrm{COC} 1$ cell line, COC1/DDP cell line, xenograft

\section{Introduction}

In 2012, approximately 239,000 women were diagnosed with ovarian cancer worldwide, while 152,000 women succumbed to the disease (1). These data suggest that mortality is observed in almost $65 \%$ of all women with ovarian cancer, and the mortality rates are even higher in women diagnosed at an advanced disease stage of the disease (stage IV). Treatment of ovarian cancer primarily includes cytoreductive surgery and platinum-based chemotherapy (2). Although clinical remission is possible, the long-term outcome remains poor since the majority of patients will relapse and succumb to the disease within 5 years, with the 5 -year survival being $30 \%(3,4)$. Therefore, novel therapies need to be integrated into ovarian cancer treatment strategies in order to achieve durable clinical outcomes.

Recently, it has been reported that lanthanum complexes were effective candidate drugs in the treatment of malignant tumors (5). For instance, lanthanum complex has demonstrated considerable cytotoxicity on human cervical carcinoma cells in vitro $(6,7)$. Lanthanum chloride $\left(\mathrm{LaCl}_{3}\right)$ also significantly inhibited the growth and induced the apoptosis of leukemia cell lines, HL-60 and NB4 (8). In addition, lanthanum has been involved in the growth arrest of human gastric cancer cells (9). All these observations suggested that lanthanum, a rare earth element, has the capacity to promote anti-tumor regulation (10).

In the present study, the therapeutic effect of $\mathrm{LaCl}_{3}$ on ovarian tumors was elucidated, based on the investigation of ovarian cancer cell lines in vitro and a xenograft animal model in vivo. It was observed that $\mathrm{LaCl}_{3}$ was able to enhance the inhibitory effect of cisplatin on the cell proliferation and carcinogenesis. These data provided a solid experimental basis for the treatment of ovarian cancer, revealing a potential strong anti-tumor candidate in the treatment of this tumor.

\section{Materials and methods}

Animals. A total of 60 female BALB/C nude mice (4-6 weeks old and weighing 13-15 g) were purchased from Shanghai SLAC Laboratory Animal Co., Ltd. (Shanghai, China). All animals were housed in micro-isolator cages in a light- and temperature-controlled room under a 12/12 h light/dark cycle at $23-25^{\circ} \mathrm{C}$. All animals had free access to food and water 
according to the Guide for the Care and Use of Laboratory Animals (11). In particular, any effort was put to avoid unnecessary pain of the animals. All the animal protocols were approved by the Ethics Committee of the First Affiliated Hospital of Nanchang University (Nanchang, China).

Cell culture and treatment. A cisplatin-sensitive human ovarian cancer cell line COC1 (American Type Culture Collection, Manassas, VA, USA) was cultured in RPMI-1640 medium (Hyclone; GE Healthcare Life Sciences, Logan, UT, USA) supplemented with $10 \%$ fetal bovine serum (Hyclone; GE Healthcare Life Sciences) at $37^{\circ} \mathrm{C}$ and $5 \%$ $\mathrm{CO}_{2}$. The cisplatin-resistant subline $\mathrm{COC} 1 / \mathrm{DDP}$ was obtained by culturing $\mathrm{COC} 1$ cells in $0.2-0.5 \mu \mathrm{g} / \mathrm{ml}$ cisplatin (Sigma-Aldrich; Merck KGaA, Darmstadt, Germany) with gradually increasing concentrations for 3 weeks at $37^{\circ} \mathrm{C}$ and $5 \% \mathrm{CO}_{2}$ to finally obtain steady cisplatin resistant cells. Cells were transferred into cisplatin-free medium for $48 \mathrm{~h}$ prior to experiments.

For in vitro studies, cells were transferred into cisplatin-free medium for $48 \mathrm{~h}$ prior to experiments. $\mathrm{COC} 1$ or $\mathrm{COC} 1 / \mathrm{DDP}$ cells were divided into 4 groups: The $\mathrm{LaCl}_{3}$ group in which cells were treated with $20 \mu \mathrm{g} / \mathrm{ml} \mathrm{LaCl}{ }_{3}$ (Sigma-Aldrich; Merck KGaA); the cisplatin group in which cells were treated with $20 \mu \mathrm{g} / \mathrm{ml}$ cisplatin (Sigma-Aldrich; Merck KGaA); the $\mathrm{LaCl}_{3} /$ cisplatin group in which cells were treated with $20 \mu \mathrm{g} / \mathrm{ml}$ $\mathrm{LaCl}_{3}$ and $20 \mu \mathrm{g} / \mathrm{ml}$ cisplatin; and the control group in which the cell were left untreated. Cells were cultured on 96 well at a density of $1 \times 10^{4}$ cells/well.

For the cells prepared for injection into mice, the medium was replaced by fresh medium in order to remove dead and detached cells at 3-4 h before harvesting. Cells were centrifuged at $251 \mathrm{x} \mathrm{g}$ for $4 \mathrm{~min}$ at room temperture, washed twice with phosphate-buffered saline (PBS) and stored on ice. Cells were suspended in $300 \mu 1 \mathrm{PBS}$ containing $2.0 \times 10^{6}$ cells per injection.

Xenograft animal model of ovarian cancer. The inoculation area of the mice was cleaned and sterilized with ethanol and iodine solutions. $\mathrm{COC} 1$ or COC1/DDP cells were injected subcutaneously into nude mice at the scapular region. An evident tumor (200-300 $\left.\mathrm{mm}^{3}\right)$ was observed 4 weeks after cell injection. At that time, 6 mice were anesthetized using $45 \mathrm{mg} / \mathrm{kg}$ pentobarbital by intraperitoneal injection, an incision was made to expose the abdomen and ovary, then tumor tissues were dissected from the nude mice and cut into the small sections $\left(\sim 10 \mathrm{~mm}^{3}\right)$. Then, the tumors were subsequently transplanted into the ovaries of the other 40 mice. At 3 weeks after transplantation, the incision was opened again and the tumor size was measured. Then mice were injected with tumor cells were further divided into 4 groups with 5 mice in each group. The $\mathrm{LaCl}_{3}$ group was treated with $10 \mathrm{mg} / \mathrm{kg} \mathrm{LaCl}{ }_{3}$ by intraperitoneal injection. The cisplatin group was treated with $10 \mathrm{mg} / \mathrm{kg}$ cisplatin by intraperitoneal injection. The $\mathrm{LaCl}_{3} /$ cisplatin group was treated with $10 \mathrm{mg} / \mathrm{kg} \mathrm{LaCl}$ and $10 \mathrm{mg} / \mathrm{kg}$ cisplatin by intraperitoneal injection. The control group was treated with $0.5 \mathrm{ml} 0.9 \%$ sodium chloride solution by intraperitoneal injection. Each treatment was given once a week for 4 weeks. Mice were sacrificed at 4 weeks after each corresponding treatments, tumor tissues were then dissected from the ovaries and the tumor volume was calculated according to the following formula: Volume $\left(\mathrm{mm}^{3}\right)=$ length $\mathrm{x}$ width $\mathrm{x}$ height $\mathrm{x} \pi / 6$.

Terminal deoxynucleotidyl transferase-mediated dUTP nick end labeling (TUNEL) assay. TUNEL assay was performed using an in situ cell death detection kit (Santa Cruz Biotechnology, Inc., Dallas, TX, USA). Briefly, cells were cultured for $48 \mathrm{~h}$ after $\mathrm{LaCl}_{3}$, cisplatin or combined of $\mathrm{LaCl}_{3}$ and cisplatin treatment. Then cells were fixed with $4 \%$ paraformaldehyde and permeabilized with $0.2 \%$ Triton X-100. Subsequently, fragmented DNA was labeled with fluorescein-12-dUTP (Thermo Fisher Scientific, Inc., Waltham, MA, USA) at $37^{\circ} \mathrm{C}$ for $1 \mathrm{~h}$, and the reaction was terminated by the addition of saline-sodium citrate buffer, followed by washing twice with PBS. TUNEL-positive nuclei were investigated under a fluorescent microscope (Nikon Corp., Tokyo, Japan) and counted from the entire sample.

Immunohistochemical analysis. The cells were washed in PBS, blocked for 60 min in 0.3\% Triton X-100 in PBS and 5\% bovine serum albumin. Next, samples were incubated overnight at $4^{\circ} \mathrm{C}$ with primary antibodies against: B-cell lymphoma-2 (BCL-2; cat. no. ab692; 1:500), Ki67 (cat. no. ab15580, 1:500), breast cancer 1 (BRCA1; cat. no. ab16780; 1:500), BRCA2 (cat. no. ab27976; 1:500) and excision repair cross-complementation group 1 (ERCC1; cat. no. ab2356; 1:100; all purchased from Abcam, Cambridge, UK). Horseradish peroxidase-conjugated anti-mouse secondary antibodies (cat. no. ab193651; 1:500; Abcam) was subsequently applied to the slides, and incubated for $1 \mathrm{~h}$ at room temperature. Finally, $\mathrm{DAB} / \mathrm{H}_{2} \mathrm{O}_{2}$ was added to the surface of the slide and the slides were visualized by light microscopy at a magnification of x200.

Statistical analysis. The measurement data was expressed by mean \pm standard deviation. Comparisons among groups were conducted using one-way analysis of variance followed by a Tukey post hoc test. $\mathrm{P}<0.05$ was considered to indicate differences that were statistically significant. All analyses were made using SPSS (version 20.0; IBM Corp., Armonk, NY, USA).

\section{Results}

Co-application of $\mathrm{LaCl}_{3}$ and cisplatin substantially promotes COCl cell death in vitro. TUNEL assay was conducted to evaluate the cell death following treatment with cisplatin, $\mathrm{LaCl}_{3}$ or cisplatin $+\mathrm{LaCl}_{3}$ in the $\mathrm{COC} 1$ and $\mathrm{COC} 1 / \mathrm{DDP}$ cell lines (Fig. 1A-D). The data indicated that the percentage of TUNEL-positive cells in the cisplatin-treated $\mathrm{COC} 1$ cells were significantly higher compared with that in the control group $\left(\mathrm{P}<0.001\right.$; Fig. 1E). By contrast, the addition of $\mathrm{LaCl}_{3}$ further promoted the apoptotic effect of cisplatin, leading to a markedly higher percentage of apoptotic cells in the cisplatin $+\mathrm{LaCl}_{3}$ co-treated group $(\mathrm{P}<0.001$; Fig. $1 \mathrm{C})$. However, application of $\mathrm{LaCl}_{3}$ only did not evidently affect the cell death or apoptosis (Fig. 1D). Similar results were obtained in the COC1/DDP cells (Fig. 2). Thus, it can be concluded that $\mathrm{LaCl}_{3}$ was able to enhance the apoptotic effect of cisplatin on the ovarian cancer cells. 

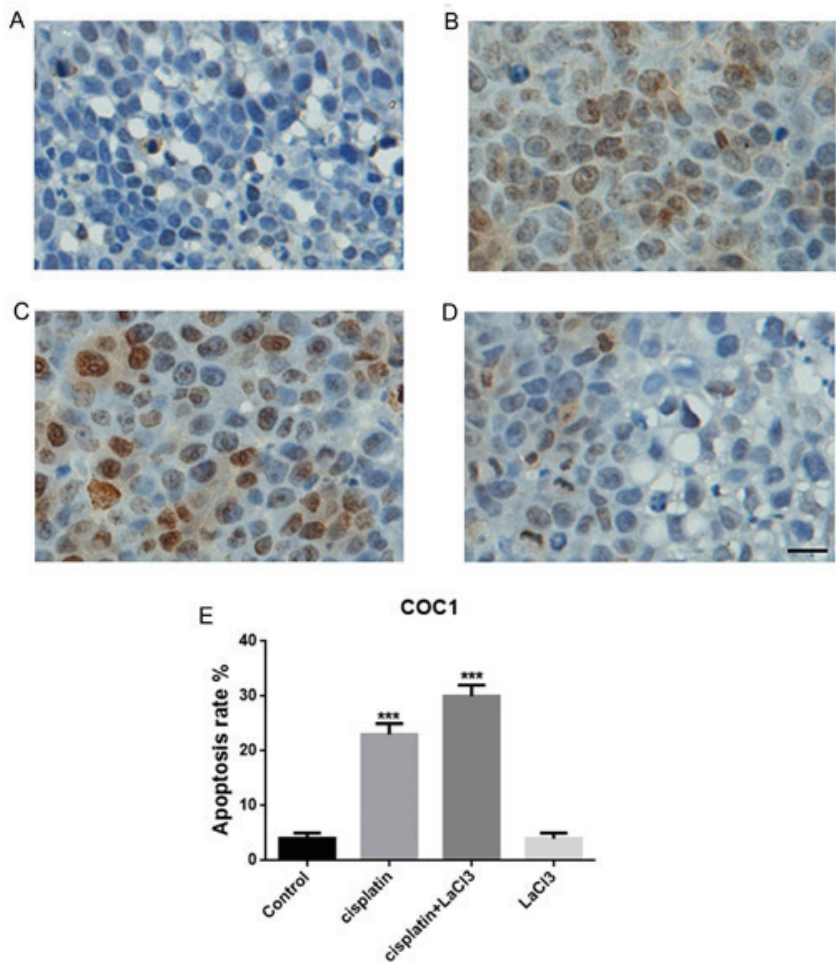

Figure 1. $\mathrm{LaCl}_{3}$ enhanced the apoptotic effect of cisplatin in $\mathrm{COC} 1$ cells TUNEL-positive cells in the (A) control, (B) cisplatin, (C) cisplatin $+\mathrm{LaCl}_{3}$, and (D) $\mathrm{LaCl}_{3}$ alone groups, (E) Quantification of apoptosis rates for different group of cells. The number of TUNEL positive cells was increased in the cisplatin-treated cells compared with the control cells. In addition, $\mathrm{LaCl}_{3}$ with cisplatin further increased the ratio of TUNEL positive cells, while $\mathrm{LaCl}_{3}$ alone did not have an evident effect on the number of apoptotic cells. Scale bar, $20 \mu \mathrm{m}$. ${ }^{* * *} \mathrm{P}<0.001$ vs. the control group. $\mathrm{LaCl}_{3}$, lanthanum chloride; TUNEL, terminal deoxynucleotidyl transferase-mediated dUTP nick end labeling.

Combination of $\mathrm{LaCl}_{3}$ and cisplatin affects the expression of tumor-associated proteins. Next, the present study determined whether the co-application of $\mathrm{LaCl}_{3}$ is able to alter the expression of tumor-associated proteins. Firstly, the expression of proliferative cell marker Ki67 in COC1 cells was decreased in the presence of cisplatin as compared with the control cells (Fig. 3A). $\mathrm{LaCl}_{3}$ stimulation together with cisplatin further decreased the expression of Ki67. By contrast, the effect of $\mathrm{LaCl}_{3}$ on the $\mathrm{Ki} 67$ expression was minor. The expression of $\mathrm{BCL}-2$, an oncogene and anti-apoptotic protein, was also examined, and presented a trend similar to Ki67 (Fig. 3A and B). On the contrary, the expression levels of human tumor suppressor genes, BRCA1 and BRCA2, exhibited the opposite results (Fig. 3C and D, respectively). Namely, the application of cisplatin alone increased the expression levels of BRCA1 and BRCA2, while co-treatment with cisplatin and $\mathrm{LaCl}_{3}$ further increased the expression levels of BRCA1 and BRCA2. Furthermore, the current study also detected the expression of ERCC1, which is responsible for DNA repair, and identified a similar pattern to that of Ki67 and BCL-2, with a decrease observed in ERCC1 expression in the cisplatin and cisplatin $+\mathrm{LaCl}_{3}$ groups (Fig. 3E). In the COC1/DDP cells, all the results were similar with those observed in the COC1 cells (Fig. 4). Collectively, the immunochemical data indicated that $\mathrm{LaCl}_{3}$ and cisplatin combined treatment decreased the expression
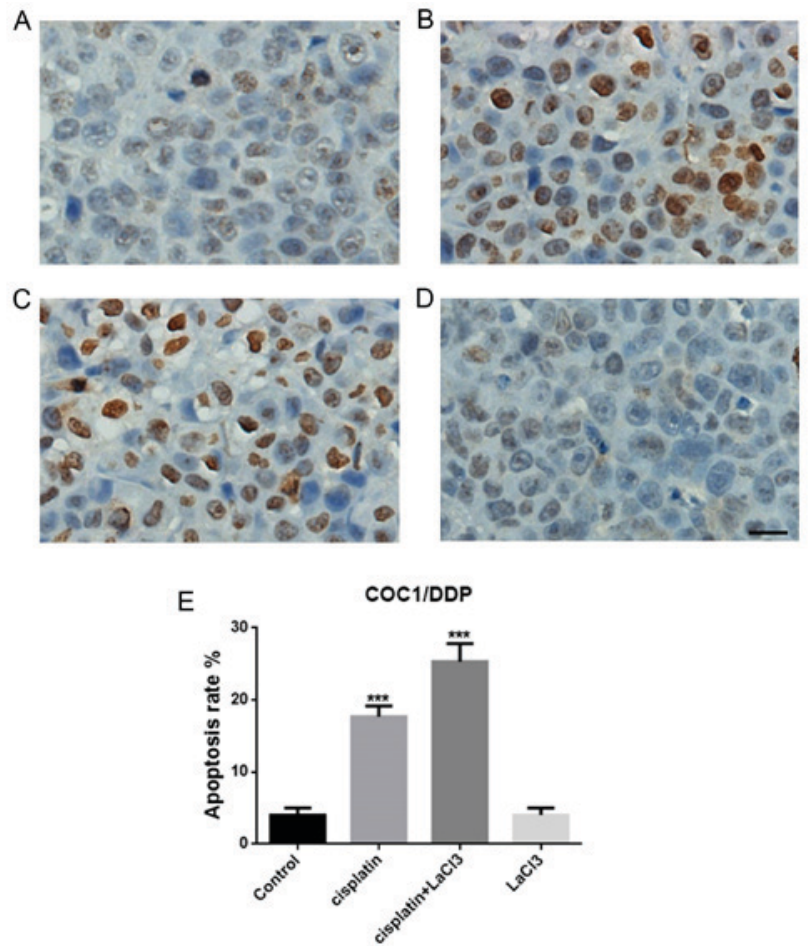

Figure 2. $\mathrm{LaCl}_{3}$ enhanced the apoptotic effect of cisplatin in COC1/DDP cells TUNEL-positive cells are shown in the (A) control, (B) cisplatin-treated, (C) cisplatin $+\mathrm{LaCl}_{3}$-treated, and (D) $\mathrm{LaCl}_{3}$-treated groups. (E) Quantification of apoptosis rates for different group of cells. Scale bar, $20 \mu \mathrm{m} .{ }^{* * *} \mathrm{P}<0.001$ vs. the control. $\mathrm{LaCl}_{3}$, lanthanum chloride; TUNEL, terminal deoxynucleotidyl transferase-mediated dUTP nick end labeling.

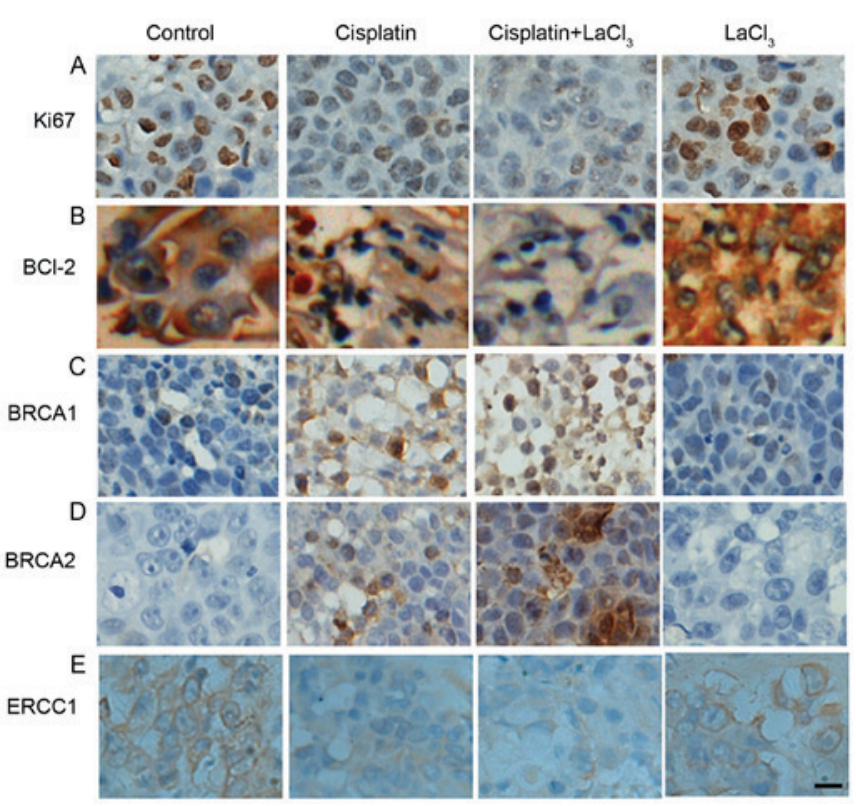

Figure 3. $\mathrm{LaCl}_{3}$ and cisplatin co-treatment altered the expression levels of tumor-associated proteins in COC1 cells. Expression levels of (A) Ki67, (B) BCL-2, (C) BRCA1, (D) BRCA2, and (E) ERCC1 are demonstrated. Ki67 expression decreased in the presence of cisplatin compared with the control, while application of cisplatin $+\mathrm{LaCl}_{3}$ further decreased $\mathrm{Ki} 67$ expression, and $\mathrm{LaCl}_{3}$ alone had only a minor effect. Similar results were obtained for BCL-2 and ERCC1 expression levels. By contrast, cisplatin increased the expression levels of BRCA1 and BRCA2 compared with the control cells, while co-application of $\mathrm{LaCl}_{3}$ and cisplatin further increased the levels, and $\mathrm{LaCl}_{3}$ alone did not have a marked effect. Scale bar, $20 \mu \mathrm{m}$. Magnification, x200. $\mathrm{LaCl}_{3}$, lanthanum chloride; BCL-2, B-cell lymphoma-2; BRCA, breast cancer; ERCC1, excision repair cross-complementation group 1. 


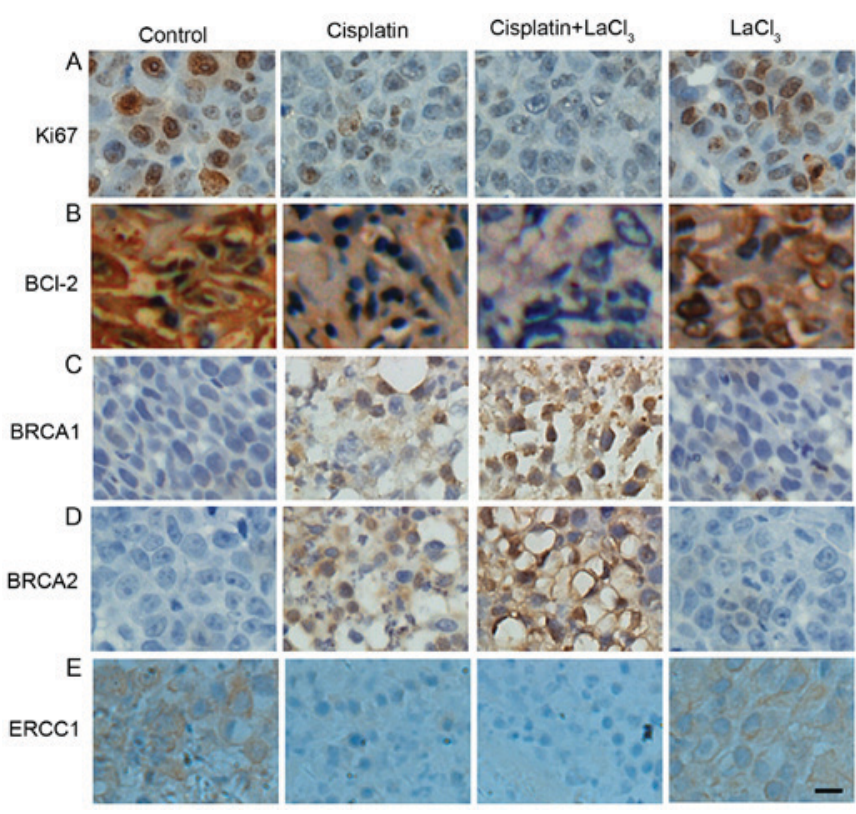

Figure 4. Co-treatment with $\mathrm{LaCl}_{3}$ with cisplatin altered the expression levels of (A) Ki67, (B) BCL-2, (C) BRCA1, (D) BRCA2, and (E) ERCC1 in $\mathrm{COC1} / \mathrm{DPP}$ cells. The effects of different treatments were similar with those in $\mathrm{COC} 1$ cells. Scale bar, $20 \mu \mathrm{m}$. Magnification, $\mathrm{x} 200 . \mathrm{LaCl}_{3}$, lanthanum chloride; BCL-2, B-cell lymphoma-2; BRCA, breast cancer; ERCC1, excision repair cross-complementation group 1.

of proteins associated with proliferation and oncogenesis, and increased the expression of tumor suppressor protein.

$\mathrm{LaCl}_{3}$ and cisplatin co-treatment inhibits the tumor growth in vivo. The present study also evaluated whether the application of $\mathrm{LaCl}_{3}$ and cisplatin affected the tumor growth in vivo. The tumor xenograft animal model, established using $\mathrm{COC} 1$ cells, demonstrated that cisplatin and $\mathrm{LaCl}_{3}$ co-incubation was able to inhibit the tumor growth in vivo (Fig. 5A). Cisplatin treatment significantly reduced the tumor weight and size by 47 and $54 \%$, respectively $(\mathrm{P}<0.001$; Fig. 5B and C). Co-application of cisplatin and $\mathrm{LaCl}_{3}$ further and significantly decreased the tumor weight and size by 56 and $66 \%$, respectively, compared with those in the control animals $(\mathrm{P}<0.001)$. By contrast, $\mathrm{LaCl}_{3}$ alone did not affect the tumor growth. The xenograft of COC1/DDP cells demonstrated similar results (Fig. 6). These findings indicated that $\mathrm{LaCl}_{3}$ exerted an inhibitory effect on the in vivo growth of ovarian tumor.

\section{Discussion}

In the present study, it was observed that $\mathrm{LaCl}_{3}$ promoted the cisplatin-induced inhibition of ovarian cancer cell growth and tumorigenesis in a mouse model of ovarian cancer. In addition, this process was associated with the alteration of the expression levels of specific tumor proteins. The current research provides novel in vitro and in vivo evidence to support the potential clinical application of $\mathrm{LaCl}_{3}$ in the treatment of ovarian cancer.

Although it has been previously reported that $\mathrm{LaCl}_{3}$ affects multiple tumor growth based on cell-based assays and animal experiments $(10,12-14)$, its precise biological role remains

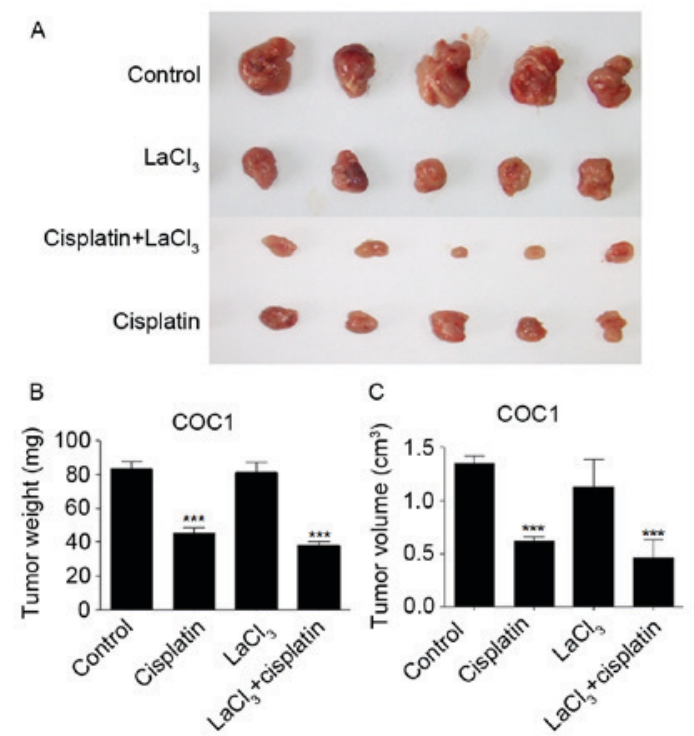

Figure 5. $\mathrm{LaCl}_{3}$ with cisplatin inhibited $\mathrm{COC} 1$ tumor growth in vivo. (A) Co-application of $\mathrm{LaCl}_{3}$ and cisplatin further decreased the size and volume of tumors, which had been decreased by cisplatin alone to a lesser extent. Statistical analysis of (B) tumor weight and (C) tumor volume is also presented. ${ }^{* * * *} \mathrm{P}<0.001$ vs. the control group. $\mathrm{LaCl}_{3}$, lanthanum chloride.

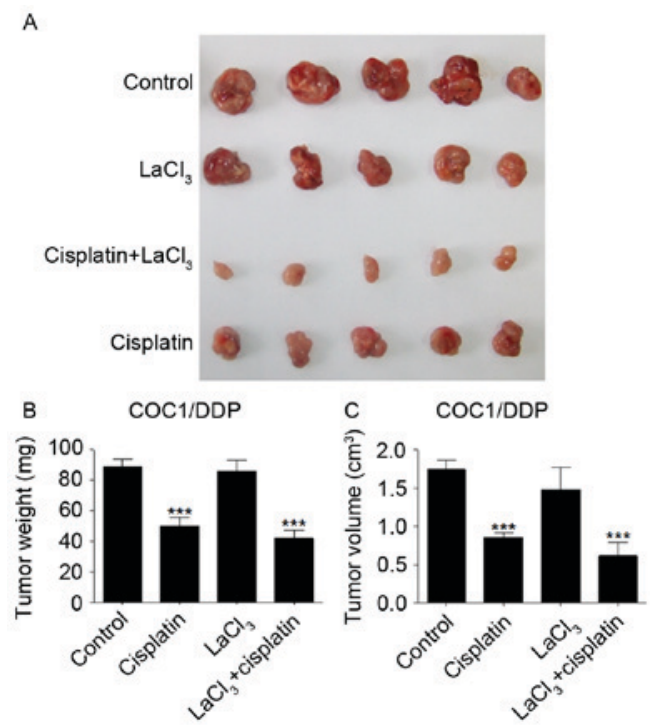

Figure 6. $\mathrm{LaCl}_{3}$ with cisplatin inhibited $\mathrm{COC1} / \mathrm{DDP}$ tumor growth in vivo. (A) Co-application of $\mathrm{LaCl}_{3}$, and cisplatin further decreased the size and volume of tumors, while cisplatin alone decreased the tumors to a lesser extent. Statistical analysis of (B) tumor weight and (C) tumor volume is also presented. ${ }^{* * * *} \mathrm{P}<0.001$ vs. the control group. $\mathrm{LaCl}_{3}$, lanthanum chloride.

largely unclear. Therefore, further investigations on the underlying mechanisms are required. The lanthanum compound KP772 has anticancer properties associated with p53-independent G0/G1 arrest and apoptosis induction (12). Apoptosis is a critical stage in the cell cycle, maintaining the balance between proliferation and cell death. In the present study, it was demonstrated that the application of $\mathrm{LaCl}_{3}$ increased the percentage of TUNEL-positive COC1 or COC1/DDP cells induced by cisplatin, indicating that $\mathrm{LaCl}_{3}$ was able to interfere with the cell cycle progression and promote apoptosis. This increased ratio of apoptotic cells was possibly due to a decrease in the 
percentage of cells in S and $\mathrm{G} 2 / \mathrm{M}$ phases and increase in the percentage of cells in G0/G1 phase. However, the cell cycle status requires further investigation in the future work.

Xenograft models, which are more biologically representative of patient tumors, are valuable models in predicting the clinical outcome (15). In the present study, using a xenograft model in nude mice, it was observed that the tumorigenesis ability of COC1 and COC1/DDP cells was reduced in the presence of $\mathrm{LaCl}_{3}$ and cisplatin, as determined by the decrease in tumor size and weight in vivo. This finding provides strong evidence on the anticancer effect of cisplatin in combination with $\mathrm{LaCl}_{3}$, though $\mathrm{LaCl}_{3}$ itself did not demonstrate an anticancer effect, it can enhance the anticancer ability of cisplatin. However, one limitation of the present study is that the phenotypic instability of tumor cells in long-term culture was not considered. A previous study has reported that xenografts derived from cell lines generally presented a more homogeneous, undifferentiated histology and thus may be different from in vitro conditions that occur during extensive culturing (16). This affects the outcome and needs to be considered in future experiments.

Through immunohistochemical analysis, the co-application of $\mathrm{LaCl}_{3}$ and cisplatin was observed to result in further downregulation of Ki67, BCL-2 and ERCC1, as well as in the upregulation of BRCA1 and BRCA2. Ki67 is a proliferative cell marker that is used as a biomarker in cancer (17), while BCL-2 is an oncogene with anti-apoptotic function (18). In addition, ERCC1 participates in DNA repair in lesions (19). Upregulation of these proteins demonstrates the weakened ability of tumor cell repair, anti-apoptosis and proliferation. By contrast, BRCA1 and BRCA2 are human tumor suppressor genes (20), and the increased expression of these two proteins indicates enhanced tumor growth suppression. Thus, in the present study, downregulation of Ki67, BCL-2 and ERCC1, as well as upregulation of BRCA1 and BRCA2, induced by $\mathrm{LaCl}_{3}$ and cisplatin indicated the suppression of cancer growth, which is direct evidence supporting the antitumor application of $\mathrm{LaCl}_{3}$ in the treatment of ovarian cancer.

In conclusion, the results of the present study suggested that the combination of cisplatin with $\mathrm{LaCl}_{3}$ was capable of inducing ovarian cancer cell apoptosis in vitro and inhibiting tumor growth in vivo. The current study provides novel evidence to establish an experimental basis for the clinical application of $\mathrm{LaCl}_{3}$ as an anticancer drug. Further studies are required to reveal the mechanism involved in the synergistic role of $\mathrm{LaCl}_{3}$ and cisplatin.

\section{Acknowledgements}

Not applicable.

\section{Funding}

No funding was received.

\section{Availability of data and materials}

The datasets used and/or analyzed during the current study are available from the corresponding author on reasonable request.

\section{Authors' contributions}

FW and YZ conducted the experiments and wrote the manuscript. SF and ShL analyzed the data. SiL designed the study.

\section{Ethics approval and consent to participate}

All the animal protocols were approved by the Ethics Committee of the First Affiliated Hospital of Nanchang University (Nanchang, China).

\section{Patient consent for publication}

Not applicable.

\section{Competing interests}

The authors declare that they have no competing interests.

\section{References}

1. Cress RD, Chen YS, Morris CR, Petersen M and Leiserowitz GS: Characteristics of long-term survivors of epithelial ovarian cancer. Obstet Gynecol 126: 491-497, 2015.

2. Petrillo M, Anchora LP, Scambia G and Fagotti A: Cytoreductive surgery plus platinum-based hyperthermic intraperitoneal chemotherapy in epithelial ovarian cancer: A promising integrated approach to improve locoregional control. Oncologist 21: 532-534, 2016

3. Baldwin LA, Huang B, Miller RW, Tucker T, Goodrich ST, Podzielinski I, DeSimone CP, Ueland FR, van Nagell JR and Seamon LG: Ten-year relative survival for epithelial ovarian cancer. Obstet Gynecol 120: 612-618, 2012.

4. Baldwin L, Ware R, Huang B, Tucker T, Goodrich S, Podzielinski I, DeSimone C, Ueland F, van Nagell J and Seamon L: Ten-year relative survival for epithelial ovarian cancer. Gynecol Oncol 120 (Suppl 1): S34-S35, 2011.

5. Kapoor S: Lanthanum and its rapidly emerging role as an anti-carcinogenic agent. J Cell Biochem 106: 193, 2009.

6. Durgo K, Halec I, Sola I and Franekić J: Cytotoxic and genotoxic effects of the quercetin/lanthanum complex on human cervical carcinoma cells in vitro. Arh Hig Rada Toksiko 62: 221-227, 2011.

7. Shen L1, Lan Z, Sun X, Shi L, Liu Q and Ni J: Proteomic analysis of lanthanum citrate-induced apoptosis in human cervical carcinoma SiHa cells. Biometals 23: 1179-1189, 2010.

8. Dai Y, Li J, Li J, Yu L, Dai G, Hu A, Yuan L and Wen Z: Effects of rare earth compounds on growth and apoptosis of leukemic cell lines. In Vitro Cell Dev Biol Anim 38: 373-375, 2002.

9. Shi P and Huang ZW: Proteomic detection of changes in protein synthesis induced by lanthanum in BGC-823 human gastric cancer cells. Biometals 18: 89-95, 2005.

10. Zhang J, Li Y, Hao X, Zhang Q, Yang K, Li L, Ma L, Wang S and $\mathrm{Li}$ X: Recent progress in therapeutic and diagnostic applications of lanthanides. Mini Rev Med Chem 11: 678-694, 2011.

11. The guide for the care and use of laboratory animals. Ilar J 56, 2015.

12. Heffeter P, Jakupec MA, Körner W, Chiba P, Pirker C, Dornetshuber R, Elbling L, Sutterlüty H, Micksche M, Keppler BK and Berger W: Multidrug-resistant cancer cells are preferential targets of the new antineoplastic lanthanum compound KP772 (FFC24). Biochem Pharmacol 73: 1873-1886, 2007.

13. Heffeter P, Jakupec MA, Körner W, Wild S, von Keyserlingk NG, Elbling L, Zorbas H, Korynevska A, Knasmüller S, Sutterlüty $\mathrm{H}$, et al: Anticancer activity of the lanthanum compound [tris(1,10-phenanthroline)lanthanum(III)]trithiocyanate (KP772; FFC24). Biochem Pharmacol 71: 426-440, 2006.

14. Zhang Z, Wang J, Li J and Xu S: Telomerase-mediated apoptosis of chicken lymphoblastoid tumor cell line by lanthanum chloride. Biol Trace Elem Res 144: 657-667, 2011.

15. Rubio-Viqueira B, Jimeno A, Cusatis G, Zhang X, Iacobuzio-Donahue C, Karikari C, Shi C, Danenberg K, Danenberg PV, Kuramochi H, et al: An in vivo platform for translational drug development in pancreatic cancer. Clin Cancer Res 12: 4652-4661, 2006. 
16. Hausser HJ and Brenner RE: Phenotypic instability of Saos-2 cells in long-term culture. Biochem Biophys Res Commun 333: 216-222, 2005

17. Kos Z and Dabbs DJ: Biomarker assessment and molecular testing for prognostication in breast cancer. Histopathology 68: 70-85, 2016

18. Cleary ML, Smith SD and Sklar J: Cloning and structural analysis of cDNAs for bcl-2 and a hybrid bcl-2/immunoglobulin transcript resulting from the $\mathrm{t}(14 ; 18)$ translocation. Cell 47: 19-28, 1986.

19. van Duin M, de Wit J, Odijk H, Westerveld A, Yasui A, Koken MH, Hoeijmakers JH and Bootsma D: Molecular characterization of the human excision repair gene ERCC-1: cDNA cloning and amino acid homology with the yeast DNA repair gene RAD10. Cell 44: 913-923, 1986.
20. Duncan JA, Reeves JR and Cooke TG: BRCA1 and BRCA2 proteins: Roles in health and disease. Mol Pathol 51: 237-247, 1998. International (CC BY-NC-ND 4.0) License. 